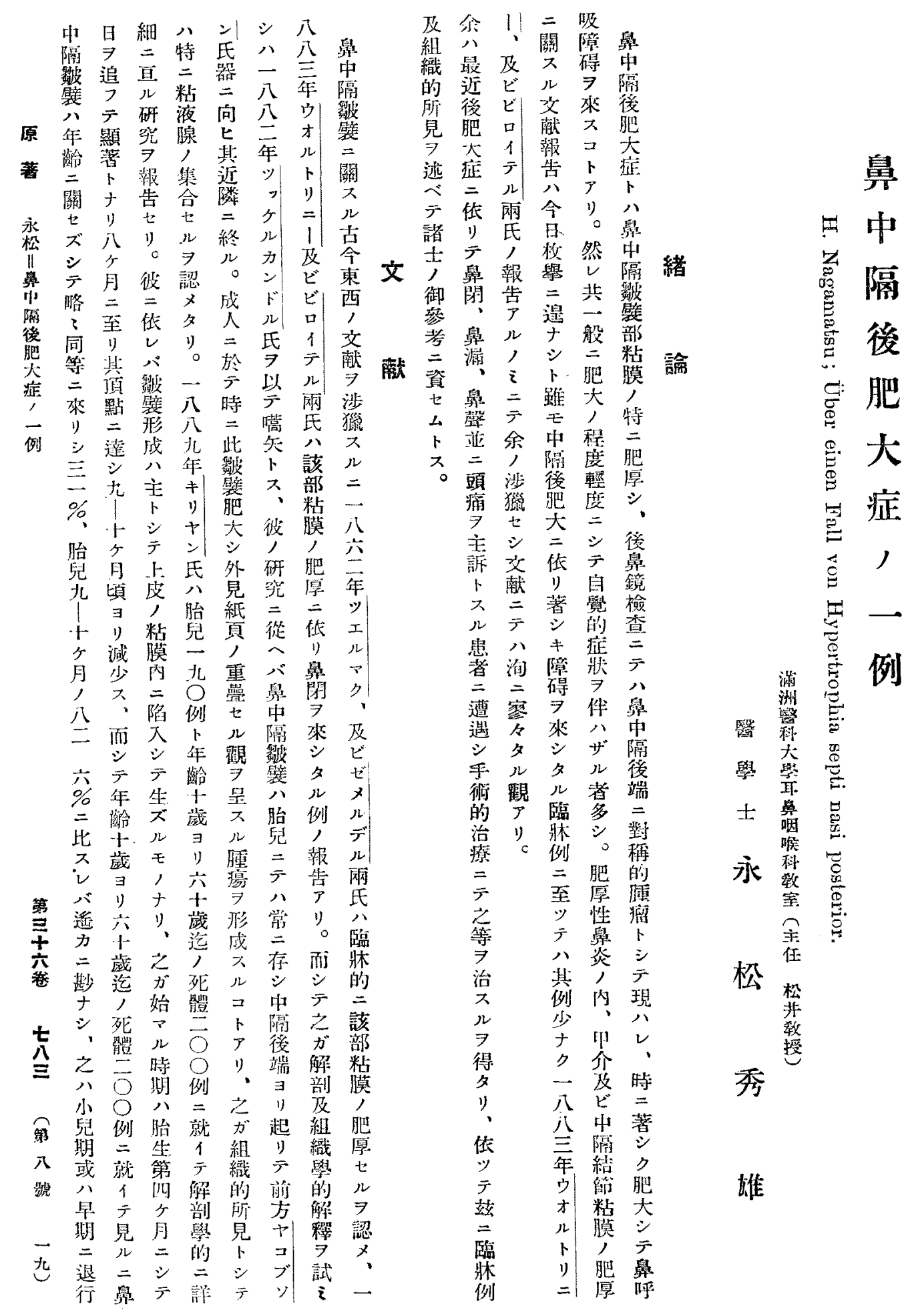




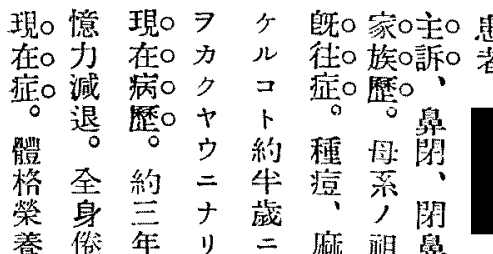

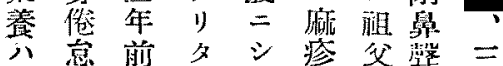

其痕 $コ$ ル其舟・西

可勞少士渐示三鼠歳

良易图吉治過崄荟機實

胸白誘藏 太幼 7 血頭關

腹中因是爾.少償重士

部、共亦坐時明

諸雖 $三$ 治三䍐 $又$

器气認 ス 三著ル 韶

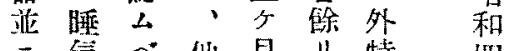

二栽へ他月り特叮

他 $キ \neq$ 間 侹記 年

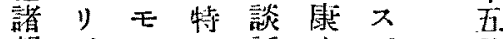

部・, 記話ナべ月

著斯ナ ス

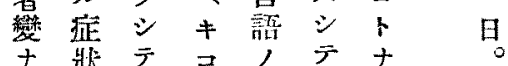

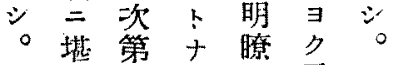

兩

鼓 ズ右。缺 邲

膜照側兵周信

三四開圍

溷年闃人 人

前瞄笑歲

店一, 八,

与 日鼻峙

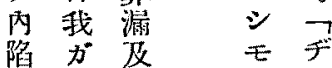

陹吕苑濑フ

自來頭 次 テ

鼠 $\exists$ 重 正. リ

的訲算常 !

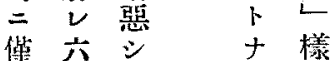

虽昨皮

難白末佔蚛

㯖永步

感 院

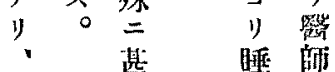

昔 洎,

艾只中治

$=$ 抽 高 燎

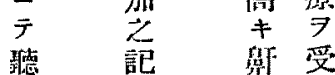

臨

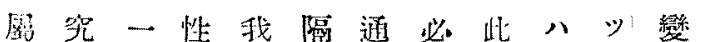

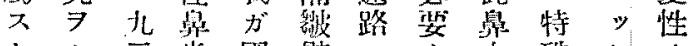

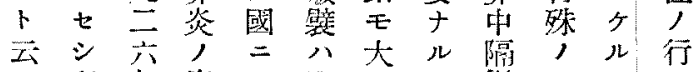

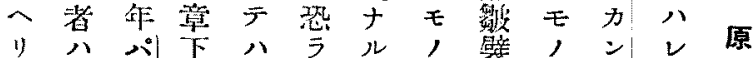

○ッッ = 则只

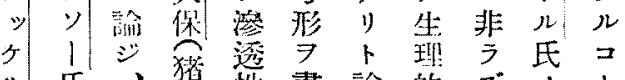

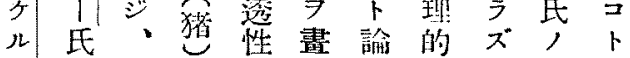

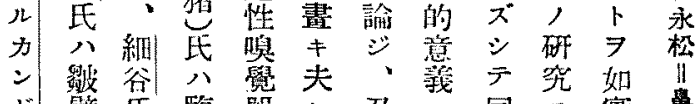

ド壁氏 臨器 $レ$ 又 $=$ 同二實

几部公牀官二作閶期

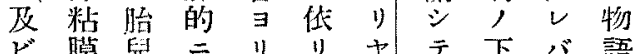

ビ膜兒二此韭自さ

工学就部洷的氏, 㝏液

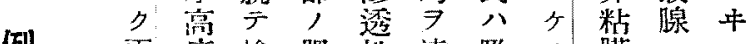

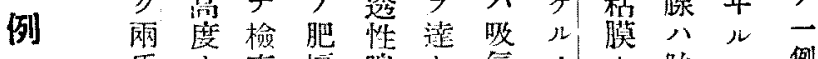

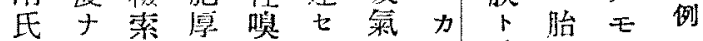

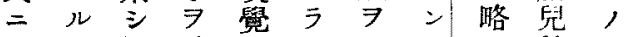

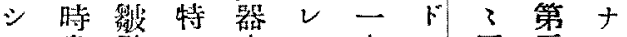

テ鼻壁二官ル定几同严

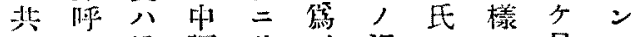

二吸男隔移: 温八二月卜

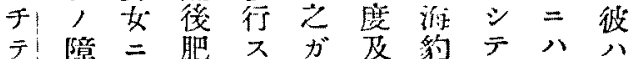

×碍區大儿消濕，台未說

儿 $\exists$ 别症際失度鼠示明

》來 $t$ : 吸 7 腔鼠存七

氏

慢之亏對保不スシ榇ル

性茂歲温ナル鼻栕モ

肥成月テ保り二中, 第

厚因二中濕卜必陑分四

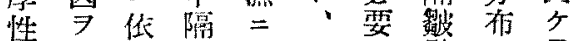

鼻炎ッ結 對一ナ壁ア月

炎症テ笷 シ

分機窉粘大九, 第》

頪轉 $\Rightarrow$ 膜

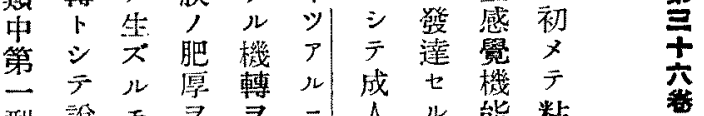

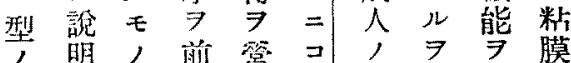

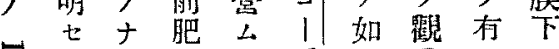

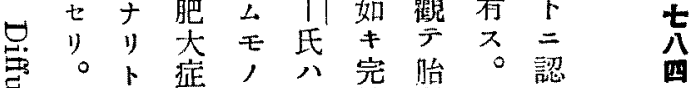

焉中云占+キ借兒 x

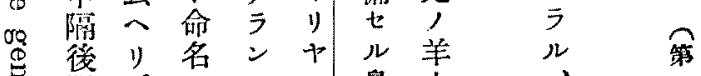

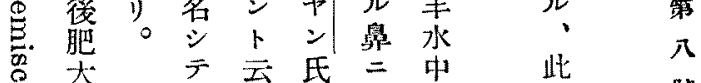

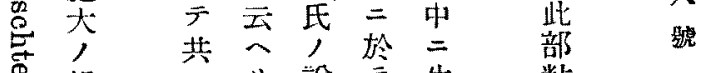

組

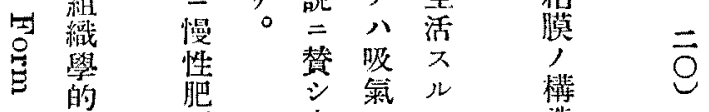




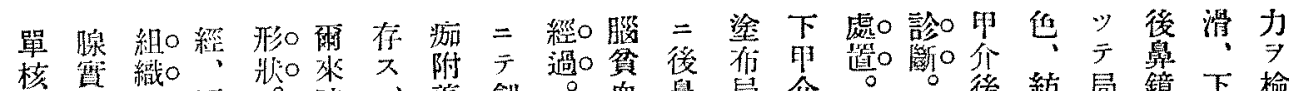

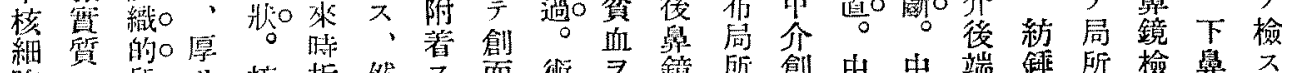

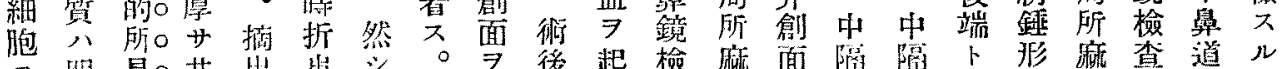
原 成骦上 $\bigcirc v=$ 四

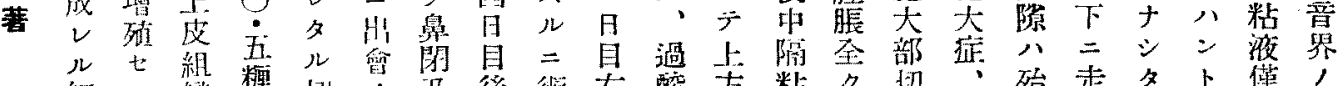

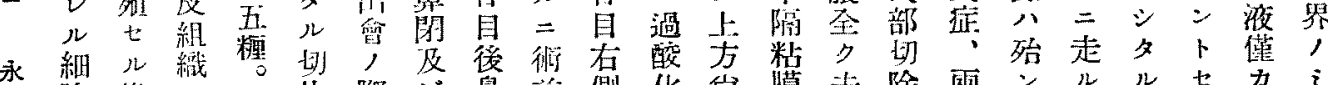

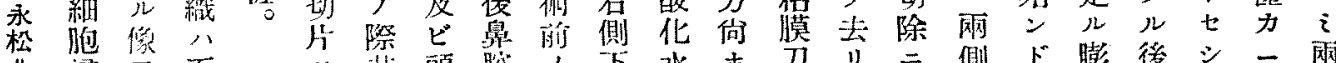

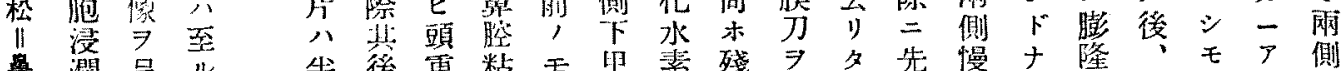

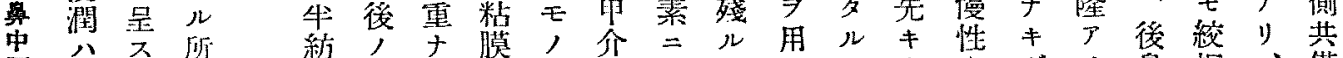
陑腺夻

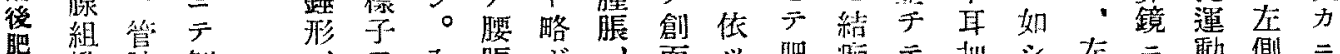

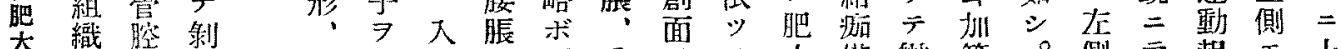

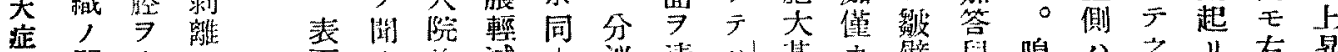
二 閔有 $、$ 面 割

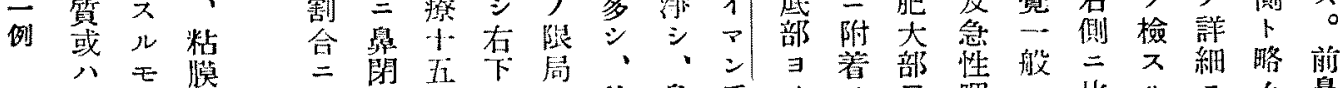

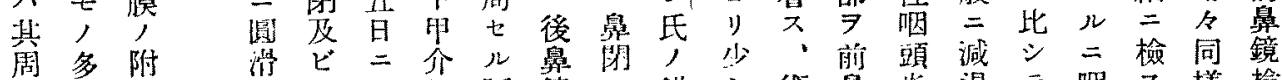

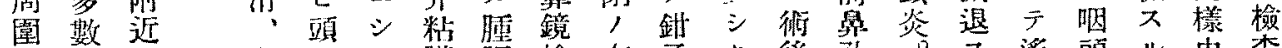

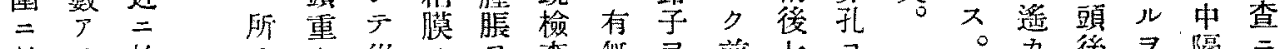

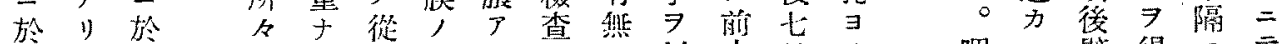

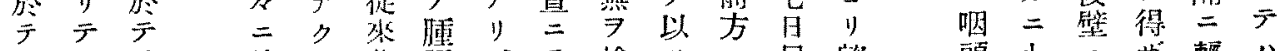

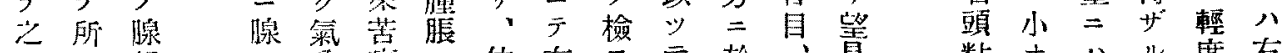

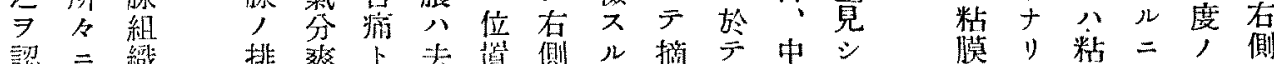

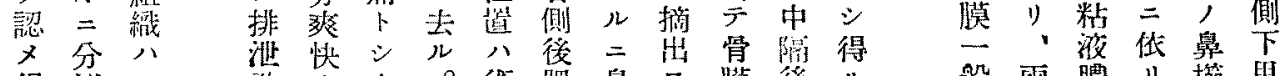

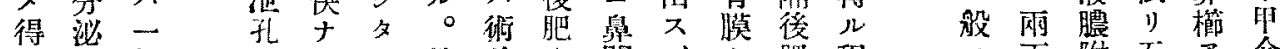

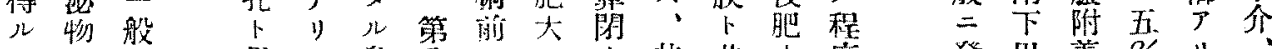
土 $\exists=$ 思卜舅八, 公, 其共大度 一容集 八テ開旦モ完シ際苆三

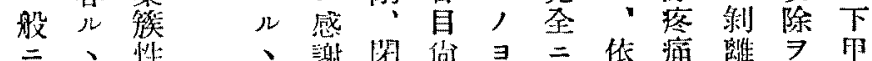

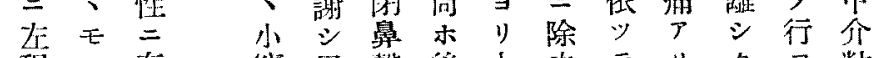

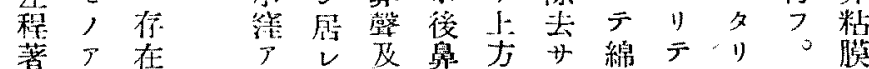

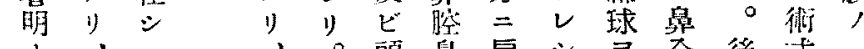

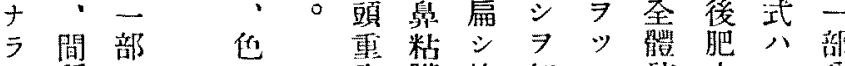

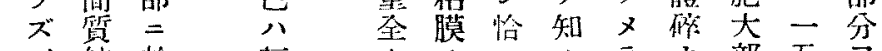

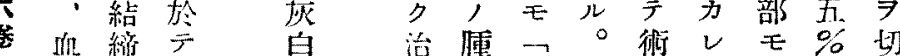

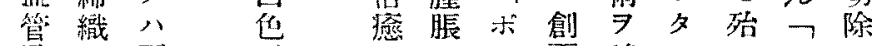

十及心可河八リ面終ルンコシ

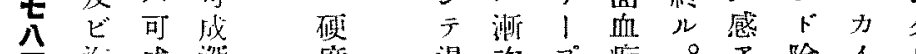

五 源: 成 深

度 綿 1) 部 骴 堆 組

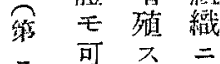
八可 公茷䡉

鯱少及縰

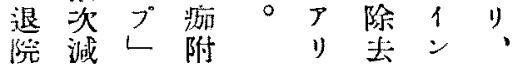
院 減

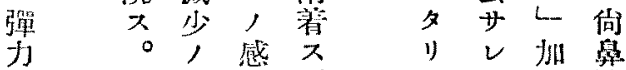

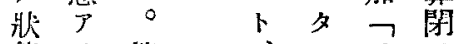

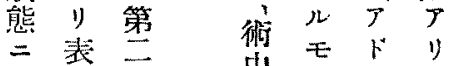

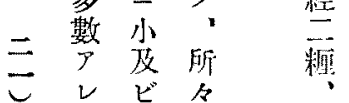

齐面百

偝貝 向二舆 东 血 龂
中, モ。

出大ナ術

慜思》惩
發 印着\% 少。

赤芥後、马 阤

テ 端 學力結

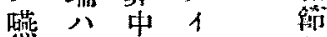

下共隔二粘

瘦二徭亡 膜

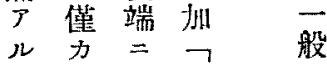

$千=八 ?=$

喉 肥叶

頭大隔 $v$ 白

$=\ulcorner\Rightarrow+$ 色

著、心り

䍩右 二 ᄂ テ

于 侧小二 嚾

シ 指浸吕

テ頭 多萌

中, 少

㵝表面頭表

肥圓缭面

大滑綿割

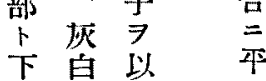




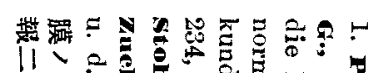

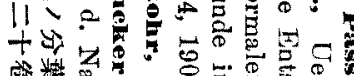

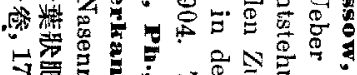

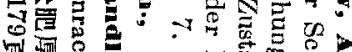

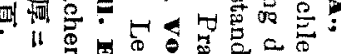

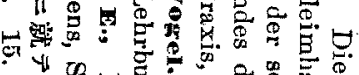

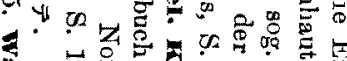

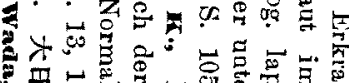

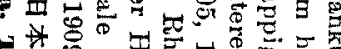

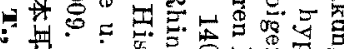

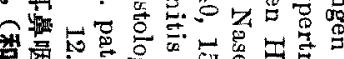

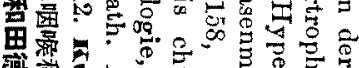

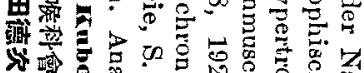

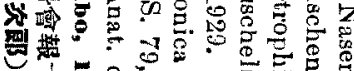
$+5 \div 0 . \overline{0}$

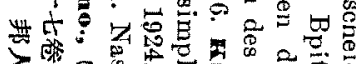

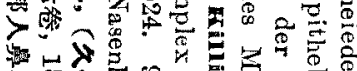

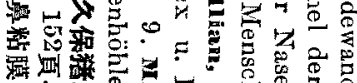

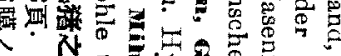

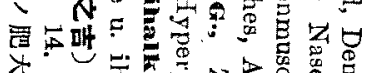
藏

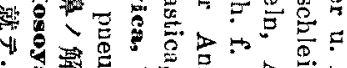

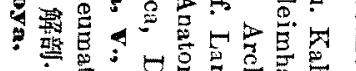

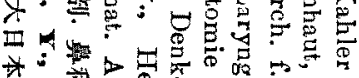

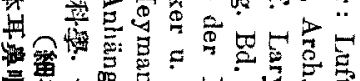

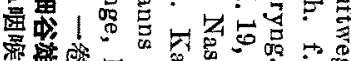

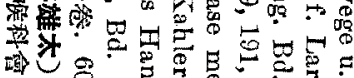

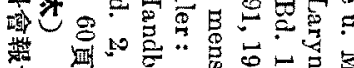

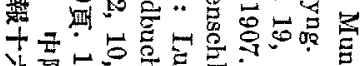

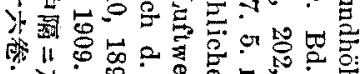

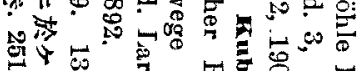

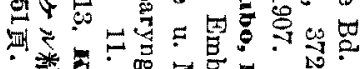

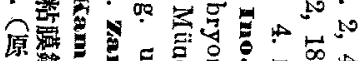

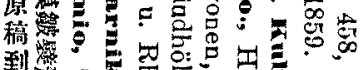

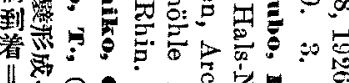

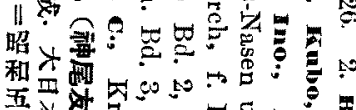

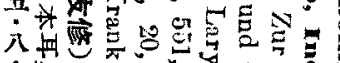

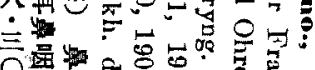

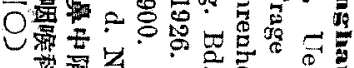

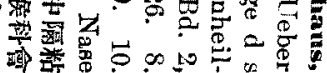

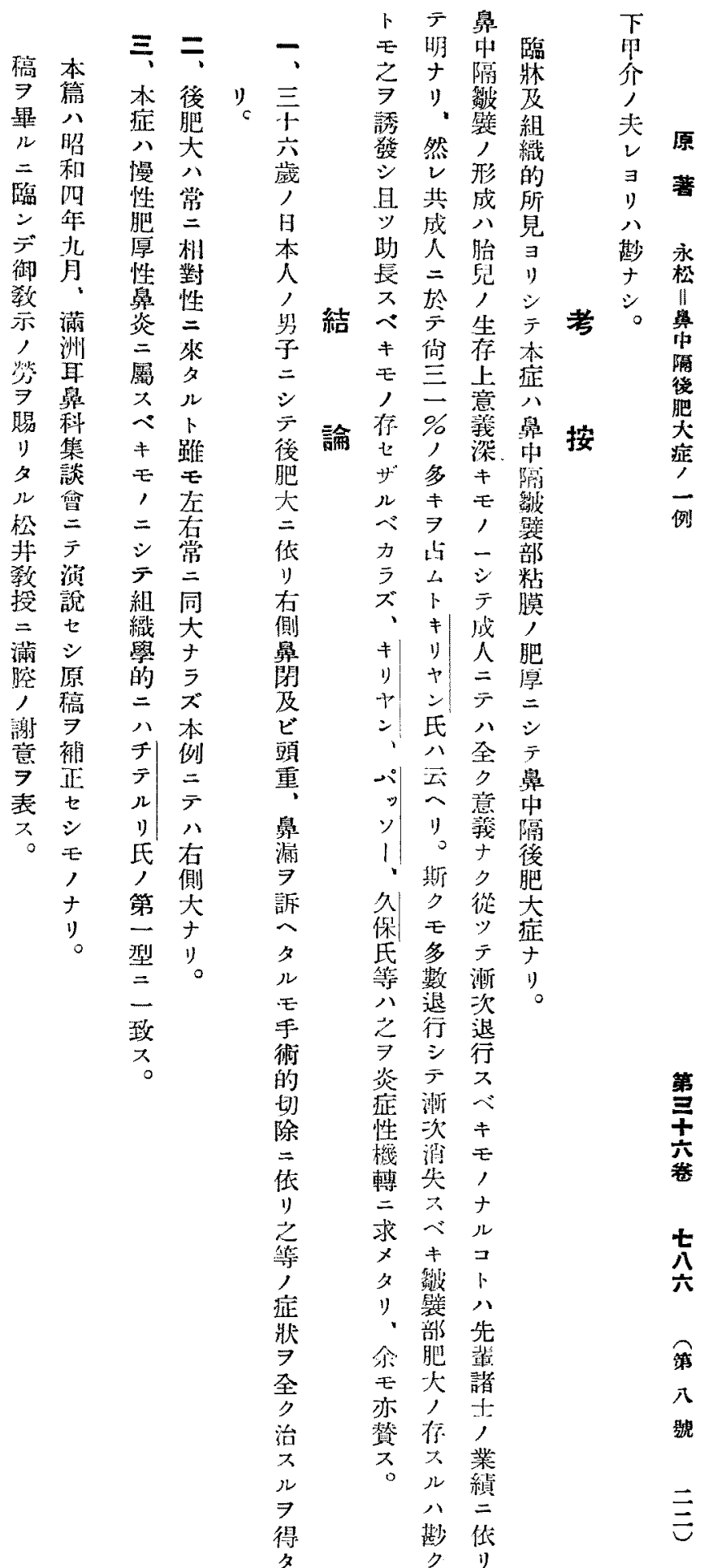


7) Die oben erwähnte Verknöcherung des Kehlkopfknorpels ist eine Teilerscheinung der degenerativen Veränderungen, die mit dem Alter das ganze Hyalinknorpelsystem befallen.

8) Die verschiedenen Erkrankungen ueben keinen besonderen Einfluss auf die Verknöcherung der Kehlkopfnorpeln aus.

(Awtoreferat.)

\title{
Ueber einen Fall von Hypertrophia septi nasi posterior.
}

Von

\section{Dr. H. Nagamatsu.}

Aus der oto-rhino-laryngologischen Klinik (Vorstand: Prof. T. Matsui), Mandschurische medizinische Hochschule, Mukden.

Ref. fühıte einen Patienten vor, einen 34 jährigen Mann, der weyen zu starker Verdickung des r. hinteren Teiles der Nasenscheidewand, Nasenverstopfung, Rhinorrhoe und Kopfweh bekommen hatte. Nach der Operation kamen diese Symptome zur Ausheilung.

\section{Statistische Studien uber Oto=, Rhino=, Laryngolo= gische Krankheiten bei Schulkindern.}

Von

\author{
Dr. R. Osawa.
}

Aus der Oto-, Rhino- und Laryngologischen Klinik der kaiserlichen Universität zu Tokyo. Vorstand: Prof. Dr. T. Masuda.

Verfasser beobachtete über 3482 Schulkinder auf oto-, rhino- und laryngologische Krankhciten. Resultate:

I. Die gesamte Prozentzahl der Ohrenkrankheiten 53.2\%; davon Zeruminal propf $40.3 \%$. Abnormität des Trommelfells 9.5\%, chronische Mittelohreiterung $2.6 \%$ Ferforation des Trommelfells $2.0 \%$, Schwerhörigkeit 1.1\%. 